\title{
QUINCE DOCUMENTOS INÉDITOS RELATIVOS A LA LLAMADA “GuERRA DE CASTAS" DE 1869
}

\author{
Víctor Manuel Esponda Jimeno
}

\section{Introducción}

$\mathrm{E}$ 1 tema de la rebelión tzotzil ocurrida en Chiapas en 1869 ha sido explorado y explotado en diferentes líneas y distintos momentos. Los documentos de la época que dieron cuenta de estos sucesos fueron los periódicos El Espiritu del Siglo y La Brújula; en ellos se encuentran datos y noticias que refieren los progresos del movimiento y de las batallas que se libraron; se reproducen en esos rotativos partes militares, avisos, exordios, etcétera, asimismo los columnistas y redactores advierten de los graves peligros que corría la "raza blanca" e insinuaban el potencial retroceso que podría experimentar la civilización si las "chusmas de indios" lograran derrotar a las fuerzas armadas que las combatían, etcétera, etcétera. Las razones y motivos de esta rebelión fueron sin duda generados por los excesos y la explotación que padecían los poblados indígenas. Las opiniones al respecto parecen

Víctor Manuel Esponda Jimeno, doctorante en Antropología por la UAM-I y estudiante del doctorado en Antropología en el Instituto de Investigaciones Antropológicas de la unAM, investigador del Centro de Estudios Superiores de México y Centroamérica de la UNICACH, cuerpo académico: Patrimonio sociocultural, especialidad: etnología. Correo electrónico: espondaj@starmedia.com. apuntar al abandono, marginación y explotación de los habitantes de dichos pueblos. El surgimiento de esta rebelión se presentó como un movimiento "milenarista", como suele ser rasgo frecuente en las sociedades "tradicionales" o "primitivas", que llevadas al límite de la intolerancia, escasez y apremio buscan válvulas de escape para liberarse del yugo opresor y reivindicar su condición y derechos. No me ocuparé más de este asunto en esta ocasión, pero es preciso subrayar que las primeras manifestaciones de este movimiento redentorio por una parte y conspiratorio por otra, eclosionaron con apariciones "divinas" y con mensajes de oráculos que convocaban y reunían grandes masas de indios, seguramente con miras confabulatorias hacia el régimen sociopolítico imperante y con posibles visos a restablecer su antiguo modelo social.

Además de esos periódicos se cuenta con las versiones plasmadas en los libros de Vicente Pineda (Historia de las sublevaciones indígenas habidas en el estado de Chiapas, 1888); Flavio Antonio Paniagua (Florinda, 1890); Cristóbal Molina (War of the Castes; Indian Uprising in Chiapas, 1867-1870, as Told by an EyeWitness, 1934); Timoteo Flores Ruiz (Guerra de Castas de 1869, 1939) y los apuntamientos consignados en

\section{5}


el Diario de Francisco Villafuerte Blanco (Diario de los años 1832-1879, 1989). Estos son los documentos de la época en que se han basado los diferentes autores modernos para estructurar sus relatos e historias.

En lo que toca a autores modernos cabe mencionar como los más relevantes a Henri Favre (Cambio y continuidad entre los mayas de México; parte tercera, "El Chalikismo", 1973), los artículos y libro de Victoria Reifler Bricker (The Indian Christ. The King, 1981) y Jan Rus (Whose Castw War? Indians, Ladinos, and the Chiapas 'CasteWar of 1869', 1983) y Prudencio Moscoso Pastrana (Rebeliones indígenas en los Altos de Chiapas, 1992). ${ }^{1}$ Con ciertas variantes el asunto es tratado por los referidos desde una misma constante: la explotación y opresión de los indios. Sin duda el tema, por su propia naturaleza y su impactante epíteto, se presta a muchas interpretaciones y distintas conclusiones. Todo análisis retrospectivo corre el riesgo de ser parcial debido a que las fuentes se nos presentan despojadas de su verdadera dimensión y expuestas bajo el particular punto de vista de quien las elabora. El vencido tiene una visión, el vencedor otra, el observador por lo consiguiente y el historiador trata de ser imparcial sin lograrlo del todo, pues en su conciencia deambula soterradamente su inevitable "carácter de clase" y en tal situación, para exonerarse un poco de responsabilidades pasadas, opta por presentar los testimonios tal y como fueron elaborados y concebidos en su momento. No hay pues conclusión definitiva en la historia, pero lo que sí debe imperar es veracidad en la exposición de los datos y qué mejor oportunidad para los estudiosos el conocerlos como fueron concebidos.

En el presente caso se dan a conocer documentos oficiales, confeccionados por servidores públicos que profundamente preocupados hicieron público un alarmante problema que amenazaba a toda la población ladina de San Cristóbal y por añadidura a otras poblaciones del estado. La situación era difícil y los recursos (humanos y materiales) escasos, además las secuelas de la Reforma mantenían al estado en un aguda crisis política y económica, pues Chiapas había suministrado de manera constante y gravosa cuantiosas fuerzas y numerario en pro de la República y para combatir a los imperialistas. El armamento con que contaba, las fuerzas chiapanecas era pobre, obsoleto y los efectivos que resguardaban al estado no eran del todo adiestrados en las artes castrenses, pues la milicia activa se hallaba destacamentada en Juchitán y Tehuantepec. La crisis económica y la inestabilidad política que privó en el estado durante más de una década fueron los detonantes principales de la rebelión indígena.

En esta rebelión tuvo parte activa el "ladino" Ignacio Fernández de Galindo, quien acompañado de su esposa Luisa Quevedo y Benigno Trejo lidereó por breve tiempo la rebelión de los indios, según dicen las fuentes, en carácter de mercenario, pagado por el propio gobierno del estado. Galindo hizo su aparición en Chiapas alrededor de 1867; entró en calidad de profesor de primeras letras y a ese oficio se dedicó hasta antes de involucrarse en la rebelión. Sin duda Galindo venía bien respaldado pues las autoridades estatales y quizás federales lo recomendaron y apoyaron para que se le brindaran todas las facilidades para levantar una carta geográfica del estado, en la que registraría estadísticas, poblaciones, distancias, fincas, ranchos, costumbres, climas, etcétera. Es evidente que dicha información le sirvió de sustento para comandar la revuelta de los indios. Como quiera que haya sido, Galindo era alguien que había venido a Chiapas por recomendación expresa y con un objetivo específico que no logró cumplir, pues luego de su rendición "voluntaria" y después de haberse firmado los convenios en la labor de Esquipulas fue capturado, hecho reo, 
$y$, tras de juicio sumario fusilado en la plaza de armas como se ilustra en la litografía que pintó Pedro Martínez (ver foto al final), en tanto que su esposa fue recluida en la casa de Recogidas donde permaneció en situación incómoda como lo indica el último documento aquí incluido.

\section{Los documentos}

El material reunido proviene del acervo del Archivo Histórico Municipal de San Cristóbal de Las Casas, y corresponde en su mayoría a las secciones "Secretaría” y “Tesorería” municipales. De éstas se hizo una selección cuidadosa y los documentos han sido ordenados de forma cronológica, con énfasis en su relevancia. Para comodidad de los lectores se optó por una transcripción modernizada respetando los arcaísmos y regionalismos, a la vez que conservando algunas abreviaturas convencionales. Los títulos que llevan los documentos se los asigné pues aparecen sin denominación e integrados al cuerpo de los expedientes en los que se encuentran. La caligrafía de ellos es bastante clara, legible y lo único que se modificó fue su ortografía. Todo el material está escrito en papel tamaño legal con tintas sepia y negra.

Con la publicación de estos documentos aspira contribuir modestamente en la difusión de hechos poco conocidos y que sin duda serán de utilidad para los estudiosos de la historia de Chiapas y en particular de aquellos que se interesan en este tema.

Comunicado acerca de las Reuniones Conspiratorias De los indios de San Miguel Mitontic, $1868^{2}$

Con esta fecha dirijo al ciudadano jefe político de ese departamento la comunicación que sigue:

En virtud de la alarma que oficialmente sabe este gobierno haber causado en esa ciudad la reunión de indios que en carácter sospechoso tiene lugar en el pueblo de San Miguel Mitontic a pretexto de la adoración de un Santo, este gobierno está dictando sus providencias para enviar prontamente fuerzas que den seguridad a esa ciudad y que apoyen las medidas que haya de tomar el gobierno para evitar de raíz el mal que pudiera amenazar a la sociedad; pero si entretanto puedan llegar esas fuerzas Ud. creyere necesario aumentar la guarnición de esa plaza, por la presente queda usted autorizado para verificarlo en el número que le sea posible armas, en la inteligencia de que ya se libra orden de la receptoría de rentas de esa misma ciudad para que cubra el presupuesto con las altas que se le presenten en revista. = Todo lo que de superior orden digo a Ud. para su inteligencia y fines correspondientes.

Y de orden del ciudadano gobernador lo traslado a usted para conocimiento del ayuntamiento que presido y en respuesta a su oficio relativo fecha de ayer.

Independencia y Libertad. Chiapa, mayo $1^{\text {ro }}$ de 1868.

$$
\text { Cardona [firma] }
$$

Ciudadano Presidente Municipal de la ciudad de San Cristóbal Las Casas.

Circular EN QUe SE INSTRUye al PRESidente MUNICIPAL PARA QUE BRINDE TODAS LAS FACILIDADES AL CIUdadano Ignacio Fernández de GaLindo Para QUe LEVANTE UNA CARTA GEOGRÁFICA DEL ESTADO, $1869^{3}$

[frente] Al margen un sello que dice $=$ Prefectura de San Cristóbal

Por circular de fecha 20 del corriente la Secretaría del Superior Gobierno Constitucional del Estado dice a la Jefatura de mi cargo lo que copio.

“En una exposición en que el ciudadano Ignacio Fernández de Galindo manifiesta el propósito que tiene de levantar la carta geográfica del Estado, y solicita 
la protección del Gobierno para que disponga que las autoridades de los departamentos le faciliten los datos necesarios al efecto, en acuerdo de esta fecha el C. Gobernador Constitucional se sirvió resolver lo siguiente = visto el anterior ocurso en que el ciudadano Ignacio Fernández de Galindo solicita se le imparta por este gobierno la protección necesaria para que pueda levantar la carta geográfica del Estado según se lo propone con el objeto de darlo ha conocer de una manera más exacta, y considerando la utilidad que reportará al Estado esta obra tan importante y tan recomendada por el superior Gobierno Nacional, accederá a dicha solicitud, y en consecuencia, libre órdenes a las autoridades políticas de los departamentos del Estado, a fin de que no impidan en manera alguna al peticionario sus ope[vuelta]raciones relativas a la referida obra, sino antes bien le faciliten y hagan proporcionar por las demás autoridades de su respectiva demarcación todos los datos estadísticos y geográficos que existan en sus archivos, excitando asimismo a las personas particulares para que tampoco ellas opongan embarazos al peticionario en el curso de su trabajos y para que le faciliten todas las noticias que sobre este particular posean, ordenando asimismo que se respeten las señales que mande poner para la ejecución de la repetida obra, así como los postes de cal y canto que mande a construir en los vértices de la triangulación de primera orden que levante, a fin de que cualquiera pueda rectificarse $=\mathrm{y}$ por disposición superior le inserto a Usted para su inteligencia y cumplimiento en la parte que le corresponda.

Traslado a Usted para su inteligencia y a fin de que se faciliten al referido Galindo todos los datos que necesite para el objeto expresado, así como el expediente o documentos relativos al fundo legal de esta ciudad, plano de la misma levantado por el señor Orozco que pueden hallarse en el archivo de esta municipalidad y el padrón de fincas rústicas y urbanas. Independencia, Constitución y Reforma.

San Cristóbal Las Casas, marzo 31 de 1869. José María Ayanegui [firma]

Ciudadano Presidente Municipal de esta ciudad. Circular en que se convoca a los ciudadanos a participar con sus personas y armas ante un posible ataque del pueblo de Chamula, 18694

[frente] Al margen un sello que dice "Municipalidad de S. Cristóbal.

Circular.

En el acto que ustedes reciban la presente, citarán a todos los individuos de sus respectivas secciones para que sin pérdida de momento se reúnan en las plazuelas de sus respectivas secciones, con las armas que cada cual tenga para estar a la defensiva de cualquier ataque que el pueblo de Chamula intente dar en contra esta población, pues se tienen partes de que se prepara dicho pueblo con este propósito. Para este objeto estarán dispuestos a recibir y obedecer las órdenes que la jefatura y comandancia militar dicte.

San Cristóbal L. C. Junio 12 de 1869.

Alejandro Trejo [firma]

José L. Salazar [firma]

Ciudadanos Jefes de cuartel de esta ciudad

Circular en Que SE DA CUenta QUe EN los PUeblos de Chamula, San Pedro y San Miguel Mitontic Se ESTÁN LLEVANDO ACABO REUNIONES CONSPIRATORIAS encabezadas por Ignacio Fernández de Galindo, su esposa y Benigno Trejo, $1869^{5}$

[Frente] Al margen un sello que dice $=$ Prefectura de San Cristóbal

Por parte que esta Jefatura recibió de los preceptores de los pueblos de Chamula, San Pedro y San Miguel Mitontic y por una información corrida en el juzgado de $1^{a}$ instancia del Ramo Criminal de esta ciudad se ha llegado a averiguar que las inmediaciones del último de los 3 pueblos referidos existe una reunión de indígenas del pueblo de Chamula en número no fijo, pero que no pasa de dos mil. De la referida información y otros más datos vagos aparece hallarse en la referida reunión el 
C. Ignacio Fernández de Galindo, su esposa y Benigno Trejo; y como se ignora hasta hoy el objeto que dicho Galindo le haya Ilevado a aquellos lugares, esta jefatura queda ocupándose de esto; pero entre tanto, se están dictando algunas providencias defensivas caso de que dicha reunión tuviera una mira hostil contra esta ciudad.

Particípolo a usted para que se sirva manifestarlo a la corporación que dignamente preside, a efecto de que con oportunidad dicte las medidas que crea conducentes a la defensa de esta población.

Independencia, Constitución y Reforma.

San Cristóbal Las Casas, junio 12 de 1869.

José María Ayanegui [firma]

Ciudadano Presidente Municipal de esta ciudad.

CoRrespondencia RELATIVA A LAS MEDIDAS QUE SE TOMARÁN PARA SOFOCAR A LOS INDÍGENAS DE CHAMUla, $1869^{6}$

Junio 13

Al C. Jefe Político.

A lo que parece, no hay tal que el pueblo vecino de Chamula intente invadir esta ciudad; al menos así se puede colegir de hechos que bien meditados no pueden dar ni producir otra cosa; y más bien es de creerse que todo sea un pretexto para impedir la elección que tendrá lugar el día de hoy. En cuya virtud, y deseando que ésta llegue a realizarse con la libertad posible, sin que obre en ella el cohecho o soborno, ni otra causa ilegal; en cumplimiento de mi deber, invito a usted para que mande dar libertad a todos los ciudadanos a fin de que se instalen las me[vuelta]sas y se pueda cumplir con lo preescrito por la ley. Bien, que, al dárseles libertad, si así lo juzgare conveniente, pudiera prevenirles su reunión después de las tres de esta tarde y darles una contraseña para el mismo objeto, si el caso lo exigiere.
Patria y Libertad

Junio 16

¡Al público!

Amagada como está la población de un ataque que por el sublevado pueblo de Chamula según parece; y como el abasto que debe proporcionarse a las fuerzas que están organizadas y al público, se ha escaseado las fuerzas y seguirá escaseándose particularmente en los días de la expedición al referido pueblo de Chamula, en donde probablemente y por virtud de las circunstancias se carecerá de todo; por el presente se excita al vecindario, para que trabaje y proporcione víveres por sus justos precios con la abundancia y prontitud que se desea. Esto no obstante, la comisión municipal encargada del abasto dictará sus providencias.

Junio 16

A los ciudadanos regidores

Vicente Rodríguez y Manuel Narváez

Teniendo que reunirse en esta ciudad un número considerable de fuerzas para pacificar a los indígenas del pueblo de Chamula; se hace muy preciso procurar a esta población esté suficientemente abastecida. En tal virtud éxito a ustedes a fin de que toquen todos los resortes que están a su alcance; para dar el lleno a tan importante comisión.

Comunicado Del JeFe Político EN QUe dA CUENTA QUE SE HA CONSTITUIDO UNA COMISIÓN PARA AUXILIAR A LAS BRIGADAS QUE SALDRÁN A COMBATIR A LOS INDIOS SUBLEVADOS, $1869^{7}$

[frente] Al margen un sello que dice = Prefectura de San Cristóbal

La Jefatura Política de mi cargo en atención de las críticas circunstancias que atraviesa la 
población por el levantamiento de los indios de Chamula y facilitar víveres para la expedición que sobre ellos debe abrirse, comisionó a los ciudadanos Ramón Franco y Juan José Bermúdez para que corrieran una suscripción voluntaria entre algunos individuos del vecindario que verificada dio por resultado, la nómina que tengo el honor de adjuntarle para que nombrando usted una comisión de ese ayuntamiento proceda a su cobro e ingreso a esa municipalidad.

Patria y Libertad.

San Cristóbal Las Casas, junio 17 de 1869.

José María Ayanegui [firma]

C. Presidente Municipal de esta ciudad.

Acuerdos tomados EN SESIONES DE CABILdos RELATIVOS A LA GUERRA DE CASTAS, $1869^{8}$

Sesión extraordinaria habida el día 12 de junio de 1869.

Reunido el ayuntamiento bajo la presidencia del C. $\mathrm{Br}$. Alejandro Trejo, se leyó, aprobó y firmó la acta anterior, y acordó: que con motivo del ultimó parte obtenido en este propio acto por un individuo del pueblo de Cha[vuelta]mula, por el que se sabe la muerte del cura y maestro de aquel pueblo, aunque no oficial ni a ciencia cierta, pero este solo hecho hace patente la hostilidad que, un gran número de aquel pueblo ya expresado, ejerce hacia esta ciudad, basado en la denuncia citada y de los datos que arroja el expediente que con tal motivo ha instruido el juzgado de $1^{\text {ra }}$ instancia del ramo criminal de este departamento, faculta al C. presidente, para que obrando según lo requieran las circunstancias, dicte todas las providencias del caso, para salvar a la población de una invasión o bien para defenderla llegado el caso. Asimismo acordó: invitar a la Jefatura Política para que sin pérdida de momento se sirva, por medio de un bando, prevenir la reunión de todos los habitantes en un punto determinado. Con lo que se terminó el acto, firmando a su constancia el C. presidente y capitulares.

Trejo $=$ Ruiz $=$ Rodríguez $=$ Mazariegos $=$ Aguilar $=$ Ramírez = José L. Salazar [firmas]Sesión ordinaria del día 29 de junio de 1869.

\section{Presidencia del C. Clemente García.}

Leída, aprobada y firmada la acta anterior, acto continuo el C. Secretario dio lectura a una comu[frente]nicación de la Secretaria del Superior Gobierno del Estado, en que participa al C. Br. Alejandro Trejo haber sido nombrado juez de $1^{\mathrm{a}}$ instancia del ramo criminal de este departamento en reemplazo del C. Manuel Rovelo, y al quedar enterado el cuerpo, la presidencia le dio posesión de su empleo con todos los requisitos de estilo, y, se retiró a ejercer sus funciones, y en seguida el cuerpo acordó lo siguiente:

1. Que se pida oficialmente al superior gobierno del Estado la suspensión de las plazas de los pueblos del departamento en atención a las graves razones que hay para ello.

2. Que se invite al C. Jefe político a fin de que prohíba que tanto los herreros de esta ciudad como los que existen en varios pueblos no fabriquen ni vendan a los indígenas armas ofensivas; $y$, que asimismo mande recoger de los expresados indios de los pueblos del departamento toda clase de armas, para así prevenir una invasión.

3. Que se dirija comunicación al C. Tesorero Municipal ordenándole que liquide y suspenda el sueldo a los preceptores y curiales por haber cesado en sus funciones el día doce del corriente con motivo de la insurrección de indios, no así a los demás empleados y dependientes de esta municipalidad por estar funcionando sin interrupción.

4. Que se aprueben las operaciones que el C. Presidente practicó en la actual revolución de indígenas, de conformidad con las facultades que el cuerpo le confirió en sesión extraordinaria del día 12 del corriente. 
5. Que se avise al público que todos los vecinos [vuelta] de esta ciudad pongan alumbrado en las calles por la noche, a fin de que el enemigo no aproveche la oscuridad para sus operaciones hostiles.

6. Que el C. regidor Flores se nombre en comisión, para que averigüe el paradero del C. regidor Santiago.

Asistieron los ciudadanos capitulares García, Mazariegos, Ruiz, Flores, Rodríguez, Aguilar, Lara, Lic. Ramírez e infrascrito secretario.

[firman]

Mazariegos $=$ Ruiz $=$ Rodríguez $=$ Aguilar $=$ Lara $=$ Ramírez = José L. Salazar

Fojas, 26 y 27

[frente] Sesión ordinaria del día 13 de julio de 1869

Presidencia del C. Manuel Mazariegos.

Leída, aprobada y firmada el acta anterior el C. secretario municipal dio cuenta con lo que sigue.

1.- Con dos oficios de la Jefatura Política, que insertos traen otros del Superior Gobierno del Estado, relativos a que este ayuntamiento proceda a la calificación de las fincas de varios ciudadanos que poseen en la jurisdicción de San Bartolomé y en su vista se acordó: que en contestación se diga: que tan pronto lo verifiquen las comisiones del seno de esta municipalidad, el cuerpo dará cuenta de sus resultado a la Secretaría General del Estado.

2.- Con otro id de la Jefatura Superior de Hacienda, en que pide noticia de los capitales registrados en la notaría de hipotecas, correspondientes á [vuelta] manos muertas, y se acordó: que el regente de la oficina respectiva emita la expresada noticia.

3.- Con una nota oficial de la preceptora, Doña Martina Madrigal, en que participa que con fecha 12 de junio último, cerró el establecimiento de enseñanza primaria de su cargo, con motivo de la revolución de indígenas, y que por la alarma que había en esta Ciudad se separó a la de Comitán en donde existe, y en su vista el cuerpo acordó: que en contestación la presidencia le prevenga que dentro de ocho días se presente a continuar en sus funciones, tanto porque el actual orden de cosas da lugar para ello, como porque tan interesante ramo no debe estar suspenso por más tiempo.

4.- Con una exposición de los ciudadanos Manuel Evaristo Gutiérrez y Manuel Ramos, pidiendo que el ayuntamiento declare suspenso los efectos del contrato de la Garita de la Merced desde el día 12 de junio próximo pasado con motivo de la revolución de indígenas, y que al mismo tiempo quede rescindido el expresado contrato por haber desaparecido sus productos que eran objeto de él; y de enterado el cuerpo acordó: que para mejor proveer, pase a dictamen del C. Sindico $1^{\text {ro }}$ de esta municipalidad.

Asistieron los ciudadanos capitulares Mazariegos $=$ Ruiz $=$ Narváez $=$ Bonifaz $=$ Rodríguez $=$ Aguilar $=$ Lara $=$ Lic. Ramírez e infrascrito secretario.

Mazariegos $=$ Ruiz $=$ Narváez $=$ Bonifaz $=$ Rodríguez Aguilar $=$ Ramírez $=$ Lara $=$ José L. Salazar [firmas]

Sesión ordinaria del día 20 de julio de 1869.

Presidencia del C. regidor $2^{\text {do }}$ Manuel Mazariegos.

Leída, aprobada, y firmada la acta anterior del C. Secretario Municipal dio cuenta con lo siguiente.

1. Con una comunicación del juez de $1^{\text {ra }}$ instancia del ramo criminal de este departamento, en que recomienda que el ayuntamiento se sirva destituir a la actual rectora, por tener varios informes malos contra ella, y no inspirar confianza para la seguridad de los reos de delitos de grave trascendencia, y en su vista, el cuerpo acordó: que para obsequiar la recomendación del $\mathrm{C}$. juez quedan especialmente nombrados en comisión los ciudadanos regidores Flores y Rodríguez, para solicitar a la persona que le sustituya cuidando que ésta reúna las cualidades necesarias.

2. Con un oficio de los ciudadanos alcaldes locales, participando que con fecha 14 del corriente entró en funciones de curial el C. Augusto Rojas en sustitución

\section{1}


del C. Nemesio Ocampo, informando al mismo tiempo que los curiales cesaron en sus funciones el día 13 de junio hasta el 23 del mismo con motivo de la guerra de castas, y se acordó que lo primero se participe oficialmente a la secretaría municipal para los efectos legales; mas respecto de lo segundo se diga en contestación a los ciudadanos alcaldes [frente]que se sirvan ampliar el informe relativo al tiempo que suspendieron en sus funciones los curiales, porque al cuerpo le consta lo contrario de lo que expresan en su nota oficial.

3. El ayuntamiento acuerda: que con motivo de que la comisión permanente de abasto informa que los tajadores se niegan a satisfacer el derecho municipal para algunas reses que han comprado con el C. Manuel L. Solórzano, por decir que son del gobierno y que la venta de éstas no causa ningún derecho, oficialmente se interrogue al C. Solórzano si sea cierto que con esta condición haya hecho la venta de las expresadas reses, para conocimiento del cuerpo.

4. Que se participe a la Secretaría municipal que con fecha 21 de junio último, cesó de ocuparse la casa de doña Clara Castañón en que estaba la escuela de niños, para el abono de réditos. $Y$

5. Considerando el ayuntamiento que el C. preceptor José Correa sin dar aviso se separó de esta ciudad en circunstancias que esta población estaba amagada por los indígenas, en cuya época personalmente hubiera cooperado a la defensa, y que al estar hasta hoy cerrado al establecimiento de su cargo cede en detrimento de la juventud, por cuanto carece de la instrucción de tan interesante ramo, a tenido a bien acordar que queda destituido del destino de preceptor de enseñanza primaria a cuyo efecto se avisará al público, a fin de que la persona que guste optar el citado empleo ocurra en forma con sujeción a [vuelta] los requisitos que acuerde el cuerpo.

Asistieron los ciudadanos capitulares Mazariegos, Ruiz, Narváez, Bonifaz, Flores, Rodríguez, Aguilar, Lara, Domínguez, Lic. Ramírez, e infrascrito secretario.
Narváez $=$ Mazariegos $=$ Ruiz $=$ Bonifaz $=$ Rodríguez $=$ Aguilar $=$ Lara.$=$ Ramírez= Domínguez= José L. Salazar [firmas]

Circular en la Que SE convoca al PUeblo Y AUTORIDADES PARA QUE SE SUMEN A LAS ACCIONES QUE SE EMPRENDERÁN PARA AFRONTAR AL ATAQUE DE LOS INDIOS SUBLEVADOS, $1869^{9}$

[frente] Agosto 13

Circular.

San Cristóbal y sus pueblos adyacentes, poblados de raza ladina están amenazados de muerte por la raza indígena y de parte del ayuntamiento y de las autoridades, deben ponerse en juego todos los medios para una eficaz y pronta salvación.

El pueblo es dueño de sus intereses y que más que ninguno se interesa en su defensa y en su conservación es muy natural que concurra a deliberar de la manera más oportuna y conveniente a prever su existencia.

Todas estas consideraciones han pesado en el ánimo del ayuntamiento que tengo la honra de prescindir para convocar al pueblo y a las autoridades, a fin de que se sirvan concurrir el viernes próximo a las 10 de la mañana en el salón de sesiones de la municipalidad a tratar en el particular; a cuyo efecto [vuelta] haga circular esta comunicación a todos los vecinos de su sección e invito a usted seguro de que tendrá la dignación de obsequiarla.

Trascripción DE UN PARTE MILITAR QUE EL JEFE POLÍTICO HACE AL PRESIDENTE MUNICIPAL DE SAN

Cristóbal INFORMÁNDOLE DE LA DERROTA QUE SUFRIERON LOS INDIOS SUBLEVADOS, $1869^{10}$

[frente] Al margen un sello que dice = Prefectura de San Cristóbal

Con fecha siete del presente dice la Secretaría del Superior Gobierno del Estado a esta Jefatura lo que sigue. 
“Habiendo tenido aviso este gobierno de que en un paraje situado entre los pueblos de San Andrés y Santa María Magdalena; existía una reunión de los indios sublevados de varios pueblos, dispuso el ciudadano gobernador que marchase sobre ellos y marchó hoy en efecto una sección compuesta de 360 guardias nacionales a las órdenes de los C.C. comandantes de batallón Crescencio Rosas y Zacarías Avendaño, y ahora que son las siete y media de la noche se ha recibido parte de que en el día han tenido dos reñidos combates en los cuales han triunfado las tropas del gobierno de muy numerosas chusmas de indios; y según el parte referido, de éste hubo una gran mortandad teniendo sólo que deplorar por parte de nuestras tropas dos muertos y algunos heridos. Mas sobre este par[vuelta]ticular nada se puede asegurar todavía a punto fijo por no haberse recibido una noticia detallada. $=$ todo lo que de superior orden me apresuro a participar a usted para su conocimiento y el de los pueblos del departamento de su mando, a quienes se servirá usted transmitir esta importante noticia."

Y cumpliendo con este superior mandato trascribo a usted para su conocimiento tan plausible noticia.

Independencia, Constitución y Reforma.

San Cristóbal Las Casas julio 8 de 1869

José María Ayanegui [firma]

Ciudadano Presidente Municipal de esta Ciudad

Oficio de Clemente García instruyendo al TESORERO PARA QUE PAGUE LOS GASTOS DE COHETES Y MÚSICA CON MOTIVO AL TRIUNFO DE LAS ARMAS Nacionales Contra los indios Sublevados, $\mathbf{1 8 6 9}^{11}$

[frente] Al margen un sello que dice: Municipalidad de San Cristóbal.

De los gastos extraordinarios del presente año pondrá usted a disposición de esta presidencia la suma de diez pesos, para pagar los cohetes y alumbrado de la serenata de anoche, por el triunfo que las armas nacionales obtuvieron sobre los indígenas de Chamula sublevados a inmediaciones de su propio pueblo. Dígolo a usted por estar investido de facultades que el ayuntamiento confiere a esta presidencia en sesión extraordinaria del día 12 de junio anterior.

Patria y Libertad.

San Cristóbal Las Casas, julio $1^{\circ}$.

Clemente García.= José L. Salazar [firma]

C. Tesorero Municipal.= recibí, García [firma]

Remigio Antonio Trujillo, rematante de la garita DE Guadalupe expone los contratiempos Que ha

TENIDO EN LOS COBROS Y PAGOS DE DERECHOS A CAUSA DE LA GUERRA DE CASTAS, $1869^{12}$

Al margen dos sellos que dicen: "Para el bienio de mil ochocientos sesenta y nueve $=$ segunda clase $=$ cincuenta centavos.

"Administración subalterna de la renta del papel sellado = Departamento del Centro".

\section{Ciudadano Presidente Municipal.}

Remigio Antonio Trujillo de este vecindario y rematante de la garita de Guadalupe de esta ciudad, con el debido respeto parezco y digo: que cuando rematé dicha Garita por el precio de veintisiete pesos siete reales al mes, no pudo ni debió preverse por mí, ni por ilustre ayuntamiento que dignamente preside, el contratiempo que he sufrido, en la garita de mi cargo. Muy lejos de nosotros la guerra de castas; de manera que no estaba a mi alcance poner condición alguna; en la escritura de remate que otorgué, referente a los gravísimos atrasos que he tenido, pues en los meses de junio y julio me contentaría con haber reunido la tercera parte de una mesada en los dos meses haciendo presente también que los meses anteriores, he tenido que ajustar las cantidades

\section{3}


con lo de mi trabajo. El perjuicio es tan notorio que no necesita prueba, porque, por desgracia, los caminos que me corresponde cuidar, son los de Moxviquil, Cuxtitali y Guadalupe, que transitados por los indígenas sublevados, éstos dejaron de hacer sus introducciones: Los cuxtitaleros, traficantes de marranos, paralizaron su giro, no sólo por temor de dichos indios sino porque han estado en el servio de las armas. Los chilontecos, yajalontecos, ocosingueros no han hecho sus introducciones en esta ciudad por lo mismo; los bachajontecos hace más de dos meses y medio que no sólo no traen un poco de panela acaso temerosos de los caminos y últimamente, todos los habitantes del estado, Ilenos de terror, nadie ha querido continuar, con sus tráficos porque temen fracasar.

Este, Sr. Presidente es un caso excepcional del remate que hice. No estaba al alcance del muy ilustre cuerpo municipal, ni de nadie. Ha sido propiamente un caso fortuito, que no cae bajo la responsabilidad de un rematante de buena fe, sino más bien, bajo la consideración del ilustre cuerpo que contemplando, el grave mal que he sufrido se ha de servir hacerme una baja que equitativamente crea que convenga, desde el principio hasta la conclusión de esta revolución, para evitar tan grande mal que he recibido. Por tanto:

Al muy ilustre cuerpo municipal, suplico que teniendo presente [vuelta] mis razones se sirva acordar lo que en ella pido por ser de justicia. Protesto no proceder de malicia.

San Cristóbal Las Casas agosto $1^{\circ}$ de 1869

Remigio Antonio Trujillo [firma]

Sesión ordinaria del día 3 de agosto de 1869

Para mejor proveer, pase a dictamen del ministerio síndico

Flavio Paniagua

José Leonardo Salazar

En la propia fecha notifiqué al c. Remigio Antonio Trujillo el decreto precedente y de quedar entendido firmó.
Remigio Antonio Trujillo Salazar [firman]

Respetable cuerpo.

El ministerio síndico dice: que bien medido el punto sobre que versa la solicitud del ciudadano Remigio Antonio Trujillo, parece ser justo lo siguiente:

El peticionario pretende se le haga una baja para no ingresar en la Secretaría Municipal la suma de veintisiete pesos ochenta y siete y medio centavos mensualmente, habiendo rematado por un año a [frente]contar desde el 14 de marzo último, los productos de la garita de Guadalupe. Según la escritura pública que se otorgó al efecto, el contrato celebrado con el ayuntamiento es de arrendamiento; y por la ley de la materia, que es la 23 , título $8^{\circ}$ partida $3^{a}$ tal solicitud no puede ser obsequiada. Va a explicarse el ministerio= el ciudadano Trujillo para hacer su petición, se funda en que, por la guerra de castas que desgraciadamente se ha iniciado entre nosotros, los comerciantes por el rumbo de Moxviquil y Guadalupe no han hecho ningunas introducciones que le produjeran alguna cosa. Y en efecto, los vecinos de la sección de Cuxtitali que trafican con cerdos han estado sobre las armas; y los de Ocosingo, Chilón y demás hasta hoy no se ha visto que ingresen. Pero no por esto es un motivo para que la municipalidad dispense a los gariteros o rematantes de una parte de la cantidad que deben situar en arcas; porque sí efectivamente no han percibido todo lo que debiera, como otros meses, los que dejaron de hacer sus introducciones en los días de la guerra, lo habrán hecho posteriormente y lo harán en lo sucesivo con frecuencia o abundancia, y así no perderán, pues las pérdidas se compensarán con las ganancias. Y como dice la propia ley citada: si un arrendatario que arrendó por dos o más años, pierde, en un año todos los frutos y en el siguiente los recoge con que profusión de manera que lo uno se compense con el otro, no hay entonces dispensa o disminución en los frutos del arrendatario o mejor dicho, derecho para pedirlo. Esto mismo sucede en el caso que nos ocupa; pueden compensarse las pérdidas con las ganancias; $y$ con forme a las doctrinas legales, donde hay la misma razón, hay la misma disposición de derecho. 
Es de opinión, pues el ministerio síndico, apoyado en la referida ley 23 , título $8^{\circ}$ partida $3^{a}$ y en razones de pública notoriedad, que por evitar la difusión determina: que no se acceda a la pretensión del Ciudadano Trujillo, porque de su admisión se perjudicarían sin razón los fondos.

San Cris[vuelta]tóbal Las = Casas, agosto, 15 de 1869.

Mariano Domínguez [firma]

Joaquín M. Ramírez [firma]

Las Casas agosto veintisiete de 1869.

De conformidad con el dictamen precedente del Ministerio Síndico y lo acordado por esta municipalidad, declarase sin lugar la presente exposición. Notifíquese.

José L. Salazar

En la propia fecha notifíqué el decreto precedente al C. Remigio Antonio Trujillo y de entendido firmó.

Salazar $=$ Remigio Antonio Trujillo[firman]

Circular Que PREVIENe QUe No PODRÁN SALIR A COMERCIAR LAS MUJERES EN LAS PLAZAS POR ESTAR suprimidas las plazas de San Pedro, San Andrés y TeneJAPA, $1869^{13}$

[frente] Al margen un sello que dice $=$ Prefectura de San Cristóbal

Estando suprimidas las plazas rematadas de los pueblos de San Pedro, San Andrés y Tenejapa, hará usted que la comisión de abasto respectiva bajo su más estrecha responsabilidad, haga que los viveres que se expenden en aquellas sean traídos a la plaza principal de esta ciudad; cuidando por la misma razón y propia responsabilidad que se impida la salida de las mujeres que acostumbran comerciar en las referidas plazas para lo que librando sus órdenes a los jefes de cuartel a fin de que formen listas de las que delinquieren y esta Jefatura aplique la pena que corresponda.

Patria y Libertad.
San Cristóbal Las Casas, julio 22 de 1869.

Ayanegui [firma]

Ciudadano Presidente Municipal de esta Ciudad

Carta de doña Martina M. DE Suasnavar preceptora DE INSTRUCCIÓN PRIMARIA DEL ESTABLECIMIENTO DE NIÑAS DE ESTA CIUDAD, EN QUE EXPONE LOS MOTIVOS QUE LE OBLIGARON A ABANDONAR ESTA CIUDAD, $1869^{14}$

La acción dada el 21 del corriente por las fuerzas del gobierno a los indígenas de Chamula, y la actitud hostil en que éstos quedaron sobre esa ciudad, me hicieron concebir temores de que no pudiendo prescindir fui obligada a salir de esta ciudad precipitadamente con toda mi familia el día 22, sin que las apremiantes circunstancias en que me hallara me hubiesen dado lugar a comunicar a usted por su honroso medio ponerlo en conocimiento de la ilustre municipalidad que cerraba el establecimiento de educación primaria de niñas que es a mi cargo por los días en que fue de muy preciso por no poderse reunir las alumnas durante la guerra que ha estallado y tiene en continua alarma esa ciudad. Lo hago ahora con aquel fin suplicando a usted se digne comunicarme oportunamente la cesación de las circunstancias que obligaron a los habitantes de esa ciudad a dispersarse para emprender inmediatamente mi marcha para ir a continuar la enseñanza.

Dios guarde a usted muchos años.

Comitán, junio 23 de 1869.

Señor Presidente Municipal de la ciudad de San Cristóbal.

Martina M. de Suasnavar [firma]

Instrucción que da el jefe político para que se mande limpiar la Ciudad, $1869^{15}$

Al margen un sello que dice $=$ Prefectura de San Cristóbal

He notado en todos lo fortines que resguardan la plaza de armas, y aún en algunos edificios públicos como la Universidad, hay tantas inmundicias que 
son verdaderamente intransitables los primeros, e inevitable el segundo en tales términos que si este mal no se corrige, de seguro podemos contar con que pronto desarrollará un tifus más desolador que la guerra de castas; por lo mismo prevengo a usted que dicte sus providencias a efecto de que la comisión de policía bajo su más estrecha responsabilidad deje hoy en estado de completo aseo y limpieza los lugares mencionados.

Patria y Libertad.

San Cristóbal Las Casas, julio 3 de 1869.

José María Ayanegui [firma]

Ciudadano Presidente Municipal de esta Ciudad

Ocurso relativo a que si la Señora Luisa Quevedo DE GaLINDO SE ENCUENTRA EN ESTADO DE GRAVIDEZ EN La CASA DE RECogidas de ESTA CiUdad, $1870^{16}$

[frente] Al margen dos sellos que dicen: Segunda clase $=$ cinco centavos $=$ para el bienio de mil ochocientos sesenta y setenta y uno.

Administración subalterna de la renta del papel sellado $=$ Departamento del Centro.

Ciudadano Presidente Municipal

Carmen Urbina rectora de recogidas de esta ciudad, ante usted como mejor lugar haya en derecho, con el debido respeto expongo: que se han esparcido voces, asegurando que doña Luisa Quevedo de Galindo, está grávida, y como hace más de un año que se halla en prisión se sugería que en esta casa de recogidas se ha dado entrada algún hombre y se han consentido actos reprobados que constituyen un delito de que yo sería responsable, quedando además humillado mi honor, el de esta casa y hasta de la municipalidad a donde han llegado esas voces, aunque no han dado paso alguno para su averiguación de que todavía es fácil, estando, como aún está en esta casa la Señora Quevedo por lo que.

Al C. Presidente: pido y suplico se sirva mandar reconocer por dos facultativos o dos matronas a la expresada señora para que si es cierto que está grávida consignemos al juez competente para que proceda a la averiguación del caso, y en caso contrario que sufra mi denunciante la pena que yo había de merecer por falso calumniador, como por haber expresado que se dieran voces que la mencionada Quevedo se había ausentado de esta ciudad para criminarme como lo ha hecho sin fundamento alguno; asimismo suplico a la corporación [frente] mandar se me de una constancia de la falsedad de las imputaciones que se me hacen para satisfacción mía de la vindicta pública. Es justicia que pido con las protestas necesarias.

San Cristóbal de Las Casas, Septiembre 6 de 1870.

De orden de mi señora abuela Carmen Urbina que no sabe escribir, hágalo yo.

Francisco A. Paniagua [firma]

Septiembre 10 de 1870

Por acordado en sesión del días de ayer, no teniendo noticia ni menos denuncia sobre el hecho a que se refiere la peticionaria declarase improcedente su escrito y petición dejando su derecho a salvo para reclamar caso estar cierta de quien la mancilla y desde ahora la casa que esta encomendada.

Vicente Rodríguez [firma] 




Notas

${ }^{1}$ Para una relación detallada de las fuentes que versan sobre este particular, véase Víctor Manuel Esponda Jimeno: "Las sublevaciones indígenas en Chiapas a través de algunas fuentes", Anuario del Instituto Chiapaneco de Cultura. Departamento de Patrimonio e Investigación, 1991, Gobierno del Estado de Chiapas, pp. 156-175.y "La rebelión tzotzil de 1869”, Homenaje al Profesor Prudencio Moscoso Pastrana, 1994, UNAM, Centro de Investigaciones Humanísticas de Mesoamérica y el Estado de Chiapas, pp. 75-79.

${ }^{2}$ Secretaría particular. Comunicados del Gobierno del Estado, Exp. 17, foja 1.

${ }^{3}$ Secretaría Municipal, 118 comunicaciones de la jefatura política, Exp. 22, foja 46.

${ }^{4}$ Secretaría municipal, 20 circulares de la presidencia municipal, Exp. 09, foja 09.

${ }^{5}$ Secretaría Municipal, 118 comunicaciones de la jefatura política, Exp. 22, foja 80.

6 Secretaría Municipal, libros de borradores de la correspondencia municipal, Exp. 03, fojas 11frente y vuelta.
${ }^{7}$ Secretaría Municipal, 118 comunicaciones de la jefatura política, Exp. 22, foja 81.

8 Secretaría Municipal. Libro de actas; expediente No. 01, foja 26.

${ }^{9}$ Secretaría Municipal, libros de borradores de la correspondencia municipal, Exp. 03, fojas 14 frente y vuelta.

10 Secretaría Municipal, 118 comunicaciones de la jefatura política, Exp. 22, foja 112.

${ }^{11}$ Tesorería Municipal, ciento cincuenta comunicados de la Tesorería Municipal. Exp. 5, foja 14.

${ }^{12}$ Secretaría Municipal, 24 avisos de varios particulares, exp. 20, fojas 13 y 14 .

${ }^{13}$ Secretaría Municipal, 118 comunicaciones de la jefatura política, Exp. 22, foja 113.

${ }^{14}$ Secretaría Municipal, comunicaciones de varios particulares, Exp. 14, foja 21.

${ }^{15}$ Secretaría Municipal, 118 comunicaciones de la jefatura política, Exp. 22, foja 108.

16 Secretaría Municipal. Escritos de particulares, expediente No. 36; foja 4.

\section{7}

